\title{
EFEKTIVITAS PENERAPAN SIA BERBASIS KOMPUTER DENGAN PENDEKATAN DBMS PADA KSP ASRI SARI UTAMA MANDIRI
}

\author{
Ni Wayan Ayu Santi \\ Jurusan Pendidikan Ekonomi, Fakultas Ekonomi dan Bisnis \\ Universitas Pendidikan Ganesha \\ Singaraja, Indonesia \\ e-mail: ayu_santi08@yahoo.com,ary.meitriana@yahoo.co.id, \\ anjumanzukhri09@gmail.com
}

\begin{abstract}
ABSTRAK
Penelitian ini bertujuan untuk mengetahui (1) penerapan sistem informasi akuntansi (SIA) berbasis komputer dengan pendekatan database management system (DBMS) pada Koperasi Simpan Pinjam (KSP) Asri Sari Utama Mandiri, dan (2) efektivitas penerapan SIA berbasis komputer dengan pendekatan DBMS pada KSP Asri Sari Utama Mandiri. Data dikumpulkan dengan metode wawancara, kuisioner dan dokumentasi, yang selanjutnya dianalisis dengan analisis deskriptif kuantitatif. Hasil penelitian menunjukkan bahwa (1) penerapan penerapan SIA berbasis komputer dengan pendekatan DBMS pada KSP Asri Sari Utama Mandiri terdiri dari tiga proses yaitu input, proses pada DBMS, dan output dan (2) efektivitas penerapan SIA berbasis komputer dengan pendekatan DBMS pada KSP Asri Sari Utama Mandiri yang diukur melalui enam indikator yaitu independensi data, standarisasi data, integrasi data, waktu, keamanan data dan variasi laporan berada pada kriteria efektif. Hal ini dapat dilihat dari perolehan masing-masing indikator, yaitu berdasarkan indikator independensi data dengan kriteria efektif (288), indikator standarisasi data dengan kriteria efektif (249), indikator integrasi data dengan kriteria efektif (314), indikator waktu dengan kriteria efektif (312), indikator keamanan data dengan kriteria efektif (260), dan indikator variasi laporan dengan kriteria sangat efektif (266).
\end{abstract}

Kata kunci: DBMS, efektivitas, dan SIA

\begin{abstract}
This research aimed to determine (1) application of accounting information systems (AIS) with a computer-based approach to database management system (DBMS) in the Credit Unions (KSP) Asri Sari Utama Mandiri, and (2) the effectiveness application of AIS with a computer based approach to DBMS In the KSP Asri Sari Utama Mandiri. Data were collected through interviews, questionnaires and documentation, which is then analyzed by quantitative descriptive analysis. The results showed that (1) the application AIS computer based approach to DBMS to KSP Sari Utama Mandiri consists of three processes namely, input, process the DBMS, and the output, and (2) effectiveness of the application AIS computer based approach to DBMS to KSP Sari Utama Mandiri that measured through six indicators of data independence, data standardization, data integration, time, data security and report variations in the criteria are effective. It can be seen from the acquisition of each indicator, which is based on indicators data independence with effective criteria (288), indicators data standardization with effective criteria (249) , indicators of data integration with effective criteria (314), an indicator of time with effective criteria (312), indicators of data security with effective criteria (260), and indicators of report variation in the criteria highly effective (266).
\end{abstract}

Keywords: DBMS, effectiveness, and AIS

\section{PENDAHULUAN}

Sistem Informasi yang memadai di suatu perusahaan dapat mendukung dan membantu manajemen dalam penyediaan informasi. Kemampuan

manajer perusahaan untuk
mengalokasikan sumber daya secara
efisien dan efektif memerlukan
informasi akuntansi sebagai salah satu
dasar penting dalam pengambilan


keputusan alokasi sumber daya. Informasi tersebut seperti laporan keuangan perusahaan, untuk menghasilkan informasi akuntansi dibutuhkan sistem informasi akuntansi.

Menurut Bodnar dan William (2006:3), sistem informasi akuntansi (SIA) merupakan kumpulan sumber daya seperti manusia dan peralatan yang dirancang untuk mengubah data keuangan dan data lainnya ke dalam informasi. Salah satu komponen dari sistem informasi akuntansi yaitu teknologi. Hadirnya teknologi, dapat membantu manajer perusahaan dalam kegiatan organisasi bisnis. Menurut Mulyadi (2001:13), "teknologi ibarat mesin untuk menjalan sistem informasi." Teknologi menangkap masukan, menjalankan model, menyimpan dan mengakses data, menghasilkan dan menyampaikan keluaran serta mengendalikan seluruh sistem.

Pada mulanya sistem informasi perusahaan dikerjakan sepenuhnya oleh manusia, kemudian sejalan dengan perkembangan teknologi, sistem informasi manual yang dikerjakan sepenuhnya oleh manusia mulai ditransformasikan ke dalam sistem berbasis komputer. Komputer tidak hanya dapat melakukan perhitungan-perhitungan dengan cepat, tetapi juga merupakan prosesor yang sangat akurat dan ekspansif. Jika dibandingkan dengan manusia, manusia sangat lamban, dan terbatas. Komputer dapat memproses ratusan transaksi dalam suatu waktu tertentu sementara manusia hanya bisa memproses satu transaksi. Hal ini terjadi karena kemampuan komputer untuk mengolah data yang jauh melebihi kecepatan manusia. Selain mempengaruhi pemrosesan dan penyimpanan data, komputer juga mempunyai dampak siginifikan terhadap pengorganisasian perusahaan, pengambilan keputusan dan pendayagunaan fungsi akuntansi.

Pekerjaan akuntan dalam menghasilkan informasi keuangan dan informasi non keuangan saat ini relatif mudah dilakukan. Hal tersebut disebabkan oleh perkembangan teknologi informasi baik itu komputer maupun telekomunikasi. Menurut Bodnar dan William (2006:13), "sistem informasi akuntansi mencangkup penggunaan teknologi informasi untuk menyediakan informasi bagi pengguna." Komputer digunakan dalam berbagai jenis sistem informasi. Teknologi informasi melibatkan komputer, tetapi juga melibatkan teknologi yang lain untuk merespon informasi. Adanya jaringan komputer juga membantu akuntan karena sistem informasi akuntansi pada perusahaan besar, menengah menggunakan jaringan komputer sebagai jaringan bagian integral dari sistem informasi akuntansi. Oleh karena itu, jaringan komputer kebutuhan informasi dari pemakai sistem informasi akuntansi tersebut dapat dipenuhi dengan lebih cepat, akurat dan risiko kesalahan yang relatif kecil. Selain itu, jaringan komputer juga dapat risiko pekerjaan yang dilakukan berulang-ulang relatif dapat dikurangi.

Komputer merupakan bagian penting dari teknologi informasi sangat membantu kualitas dari sistem informasi. Untuk mengelola informasi secara efektif menjadi sumber daya yang bernilai, pengembangan sistem informasi akuntansi modern akan lebih baik jika menggunakan komputer. Perkembangan teknologi komputer yang semakin maju, menyebabkan semakin banyak perusahaan yang menggunakan jasa komputer untuk memproses data akuntansinya. Oleh karena itu, kebutuhan informasi dari pemakai SIA tersebut dapat dipenuhi dengan lebih cepat, akurat dan risiko kesalahan yang relatif kecil. Perkembangan teknologi saat ini dapat membantu perusahaan untuk mencatat transaksi yang terjadi dalam perusahaan secara terkendali. Menurut Husein (2004:61) dengan adanya teknologi database masalah-masalah yang dihadapi seperti kekacauan dan pengulangan data, ketergantungan program data, keamanan data serta penyebaran data dapat teratasi. 
Perusahaan yang menggunakan sistem informasi berbasis komputer untuk mengolah data akuntansinya akan mengetahui konsep database. Database dapat diartikan kumpulan data yang diorganisir untuk melayani berbagai aplikasi dengan memusatkan data. Komponen database terdiri dari pemakai sistem, DBMS, database administrator (DBA) dan database fisik (DBF). Komponen utama pada database yaitu DBMS. Menurut Husein (2004:4), DBMS adalah software yang memungkinkan organisasi memusatkan data, mengelola data dengan efisien dan menyediakan akses ke data yang tersimpan oleh program aplikasi. DBMS dapat bertindak sebagai penghubung antara aplikasi program dan file-file data fisik. Ketika program aplikasi memanggil suatu data, DBMS mencari data tersebut di database dan menampilkannya pada program aplikasi.

Pada DBMS ini, data dipusatkan
pada suatu departemen dan departemen lain dapat mengakses datanya. Maka departemen-departemen lainnya tidak lagi menyimpan datanya tersendiri dan semua pemakai komputer akan bekerja pada satu perangkat yang terpusat. DBMS bertugas untuk menyimpan, memperbaiki, memanggil dan menghapus data. DBMS ini penting karena kalau tidak dikelola dengan baik, ribuan data yang ada dalam perusahaan bisa jadi tidak diolah secara maksimal, hilang atau rusak sehingga secara ekonomis merugikan perusahaan. Oleh karena itu sangat penting untuk mengetahui efektivitas penerapan sistem informasi akuntansi dengan pendekatan DBMS yang dapat dinilai dari independensi data, standarisasi data, integrasi data, waktu, keamanan data dan variasi laporan.

Koperasi Simpan Pinjam (KSP) Asri Sari Utama Mandiri membutuhkan sistem informasi akuntansi guna menjalankan aktivitas usahanya seperti memasukkan data keuangan simpan pinjam dari nasabah, sehingga menghasilkan informasi akuntansi yang akurat, relevan dan tepat waktu. KSP
Asri Sari Utama Mandiri menerapkan SIA berbasis komputer dengan pendekatan DBMS agar KSP Asri Sari Utama Mandiri dapat memberikan pelayanan yang terbaik bagi pihak ekstern maupun pihak intern. KSP Asri Sari Utama Mandiri telah menggunakan sistem informasi akuntansi berbasis komputer untuk mengolah data akuntansi sejak awal berdirinya tahun 2003. Program pertama kali yang digunakan adalah Microsoft Excel. Seiring perkembangan waktu, setelah menggunakan program ini koperasi merasakan adanya kelemahan yaitu dalam pengolahan data akuntansi tidak secara otomatis. Data akuntansi yang di-input dengan program Microsoft Excel harus diolah sendiri oleh karyawan sehingga dapat menghasilkan laporan keuangan yang dibutuhkan oleh para pemakai informasi keuangan. Melihat kelemahan tersebut, maka pada tahun 2010 koperasi menambah pengolah data akuntansinya yaitu dengan menggunakan pendekatan DBMS.

Saat ini KSP Asri Sari Utama Mandiri menerapkan pendekatan DBMS dan tetap menerapkan Microsoft Excel. Sesuai dengan pernyataan Ketua KSP Asri Sari Utama Mandiri bahwa Microsoft Excel tetap digunakan karena berfungsi sebagai back-up dan pembanding laporan keuangan yang dihasilkan dari pendekatan DBMS. Sistem informasi akuntansi berbasis komputer dengan pendekatan DBMS, pemrosesan data dilakukan oleh komputer pada KSP Asri Sari Utama Mandiri secara terintegrasi dengan satu kali pengerjaan saja. Selama menerapkan SIA berbasis komputer dengan pendekatan DBMS pada KSP Asri Sari Utama Mandiri belum mengetahui tingkat efektivitas dari penerapannya, sehingga koperasi tidak mengetahui SIA dengan pendekatan DBMS sudah lebih efektif atau belum dari sistem informasi akuntansi dengan program Microsoft Excel. Padahal dengan mengetahui tingkat efektivitas penerapan SIA berbasis komputer dengan pendekatan DBMS, maka 
koperasi dapat mengukur keberhasilan dari SIA berbasis komputer dengan pendekatan DBMS yang diterapkan sudah sesuai dengan harapan. Hal ini yang melatarbelakangi diadakannya penelitian mengenai "Efektivitas Penerapan Sistem Informasi Akuntansi (SIA) Berbasis Komputer dengan Pendekatan Database Management System (DBMS) pada Koperasi Simpan Pinjam (KSP) Asri Sari Utama Mandiri."

\section{METODE}

Jenis penelitian yang digunakan dalam penelitian ini adalah penelitian deskriptif kuantitatif. Subjek dalam penelitian ini adalah KSP Asri Sari Utama Mandiri. Objek penelitian adalah penerapan SIA berbasis komputer dengan pendekatan DBMS pada KSP Asri Sari Utama Mandiri.

Data yang digunakan dalam penelitian ini berdasarkan sumbernya adalah data primer dan sekunder. Data primer yaitu hasil wawancara yang diperoleh dari mewawancarai ketua dan karyawan KSP Asri Sari Utama Mandiri dan hasil jawaban responden yang diperoleh dengan menggunakan kuisioner. Data sekunder yaitu berupa data jumlah karyawan yang diperoleh dari hasil dokumentasi.

Penelitian ini menggunakan analisis data kuantitatif berupa angkaangka yang diperoleh melalui kuisioner tentang efektivitas penerapan SIA dengan pendekatan DBMS dan data kualitatif yang diperoleh dalam penelitian ini berupa penerapan SIA dengan pendekatan DBMS pada KSP Asri Sari Utama Mandiri.

Pengumpulan data dilakukan dengan teknik wawancara memperoleh data mengenai tanggapan ketua dan karyawan dalam proses penerapan SIA berbasis komputer dengan pendekatan DBMS pada KSP Sari Asri Utama Mandiri. Kuisioner digunakan untuk mendapatkan data penelitian berupa sikap, nilai dan persepsi responden tentang efektivitas penerapan SIA dengan pendekatan DBMS. Kuisioner tersebut terdiri dari pertanyaanpertanyaan dari enam indikator yang sudah ditentukan. Pengumpulan data dengan dokumentasi berupa jumlah karyawan pada KSP Asri Sari Utama Mandiri.

Teknik analisis yang digunakan adalah teknik analisis kuantitatif, yaitu teknik analisis yang dilakukan dengan cara melakukan perhitunganperhitungan sesuai dengan rumus yang digunakan.

Menurut Sugiyono (2012:93), Skala Likert digunakan Untuk keperluan analisis kuantitatif maka jawaban tersebut diberi skor, (1) jawaban sangat positif mempunyai skor 5, (2) jawaban positif mempunyai skor 4, (3) jawaban netral mempunyai skor 3, (4) jawaban negatif mempunyai skor 2, (5) jawaban sangat negatif mempunyai skor 1 .

Rating Scale merupakan skala pengukuran data mentah yang diperoleh berupa angka kemudian ditafsirkan. Untuk menentukan persentase efektivitas penerapan SIA berbasis komputer dengan pendekatan DBMS sebagai pengolah data dicari jumlah skor yang diperoleh untuk masing-masing aspek penilaian dilakukan sebagai berikut.

a. Menentukan nilai tertinggi dan nilai terendah yang mungkin dicapai dari kuesioner yang diajukan.

Misal:

skor tertinggi yang mungkin dicapai = a skor terendah yang mungkin dicapai $=b$

b. Menentukan besarnya range skor nilai berdasarkan seluruh total skor nilai tertinggi yang mungkin dicapai dengan total skor terendah yang mungkin dicapai.

Formulasinya sebagai berikut:

Range skor $=a-b$.

c. Menentukan besarnya interval nilai berdasarkan perbandingan antara range skor nilai dengan jumlah kriteria nilai yang diperlukan. Terdapat lima kriteria meliputi:

1) Kriteria Sangat Efektif (KSE)

2) Kriteria Efektif (KE)

3) Kriteria Cukup Efektif (KCE)

4) Kriteria Kurang Efektif (KKE)

5) Kriteria Tidak Efektif (KTE) 
Formulasi: interval nilai

$\mathrm{c}=\frac{a-b}{5}$

(Sukardi. 2003:147)

d. Menentukan rentang nilai untuk masing-masing kriteria penilaian berdasarkan total skor nilai yang diperoleh masing-masing unsur dengan formulasi sebagai berikut.

1) $b+4 c<K S E \leq a$.

2) $b+3 c<K E \leq b+4 c$

3) $b+2 c<K C E \leq b+3 c$

4) $b+c<K K E \leq b+2 c$

5) $b \leq K T E \leq b+c$

e. Menentukan persentase terhadap keseluruhan pertanyaanpertanyaan yang terdapat dalam kuesioner dan menentukan efektivitas SIA berbasis komputer dengan pendekatan DBMS sebagai pengolah data dengan cara jumlah skor total yang diperoleh dibagi dengan jumlah skor ideal setelah itu dikali 100\% (Sugiyono, 2013:143).

Efektivitas penerapan SIA berbasis komputer pendekatan DBMS jika dinilai dari indikator independensi data, integrasi data, dan waktu dengan perhitungan sebagai berikut.

1) Perhitungan sub indikator

a) $a=5 \times 5=25$

$b=1 \times 5=5$

b) Range skor $=\mathrm{a}-\mathrm{b}$

$$
=25-5
$$$$
=20
$$

c) Interval: $c=\frac{a-b}{5}$

$$
\begin{aligned}
& =\frac{25-5}{5} \\
& =4
\end{aligned}
$$

Berdasarkan perhitungan yang telah dipaparkan maka rentang nilai untuk sub indikator independensi data, integrasi data, dan waktu dapat ditentukan dengan formulasi berikut.

a. Kriteria Sangat Efektif (KSE) $=21<$ KSE $\leq 25$

b. Kriteria Efektif $(\mathrm{KE})=17<\mathrm{KE} \leq 21$

c. Kriteria Cukup Efektif (KCE) $=13<$ KCE $\leq 17$ d. Kriteria Kurang Efektif $(\mathrm{KKE})=9<$ KKE $\leq 13$

e. Kriteria Tidak Efektif $(\mathrm{KTE})=5 \leq \mathrm{KTE}$ $\leq 9$

2) Perhitungan indikator

a) $\mathrm{a}=5 \times 5 \times 15=375$

$b=1 \times 5 \times 15=75$

b) Range skor $=a-b$

$$
\begin{aligned}
& =375-75 \\
& =300
\end{aligned}
$$

c) Interval: $\mathrm{c}=\frac{a-b}{5}$

$$
\begin{aligned}
& =\frac{375-75}{5} \\
& =60
\end{aligned}
$$

Berdasarkan perhitungan yang telah dipaparkan maka rentang nilai untuk indikator independensi data, integrasi data, dan waktu dapat ditentukan dengan formulasi berikut.
a. Kriteria Sangat Efektif $(\mathrm{KSE})=315$ $<$ KSE $\leq 375$
b. Kriteria Efektif $(\mathrm{KE})=255<\mathrm{KE} \leq$ 315
C. Kriteria Cukup Efektif (KCE) $=195<$ KCE $\leq 255$
d. Kriteria Kurang Efektif $(\mathrm{KKE})=135$ $<$ KKE $\leq 195$
e. Kriteria Tidak Efektif $($ KTE) $=75 \leq$ KTE $\leq 135$

Efektivitas penerapan SIA berbasis komputer pendekatan DBMS jika dinilai dari indikator standarisasi data, keamanan data dan variasi laporan dengan perhitungan sebagai berikut.

1) Perhitungan sub indikator

a) $a=5 \times 4=20$ $b=1 \times 4=4$

b) Range skor $=\mathrm{a}-\mathrm{b}$

$$
\begin{aligned}
& =20-4 \\
& =16
\end{aligned}
$$

c) Interval: $\mathrm{c}=\frac{a-b}{5}$

$$
\begin{aligned}
& =\frac{20-4}{5} \\
& =3,2
\end{aligned}
$$

Berdasarkan perhitungan yang telah dipaparkan maka rentang nilai untuk sub indikator standarisasi data, keamanan data dan variasi laporan 
dapat ditentukan dengan formulasi berikut.
a. Kriteria Sangat Efektif $(\mathrm{KSE})=16,8$ $<\mathrm{KSE} \leq 20$
b. Kriteria Efektif $(\mathrm{KE})=13,6<\mathrm{KE} \leq$ 16,8
C. Kriteria Cukup Efektif $($ KCE) $=10,4$ $<$ KCE $\leq 13,6$
d. Kriteria Kurang Efektif $(\mathrm{KKE})=7,2<$ KKE $\leq 10,4$
e. Kriteria Tidak Efektif $(\mathrm{KTE})=4 \leq$ KTE $\leq 7,2$
2) Perhitungan indikator
a) $a=5 \times 4 \times 15=300$
$b=1 \times 4 \times 15=60$
b) Range skor $=\mathrm{a}-\mathrm{b}$

$$
\begin{aligned}
& =300-60 \\
& =240
\end{aligned}
$$
c) Interval: $\mathrm{c}=\frac{a-b}{5}$

$$
\begin{aligned}
& =\frac{300-60}{5} \\
& =48
\end{aligned}
$$

Berdasarkan perhitungan yang telah dipaparkan maka rentang nilai untuk indikator standarisasi data, keamanan data dan variasi laporan dapat ditentukan dengan formulasi berikut.

a. Kriteria Sangat Efektif $($ KSE) $=264<$ KSE $\leq 300$

b. Kriteria Efektif $(K E)=216<K E \leq 264$

c. Kriteria Cukup Efektif $(\mathrm{KCE})=156<$ KCE $\leq 216$

d. Kriteria Kurang Efektif $($ KKE) $=108<$ KKE $\leq 156$

e. Kriteria Tidak Efektif $($ KTE) $=60 \leq$ KTE $\leq 108$

Perhitungan indikator keseluruhan, yaitu membuat perhitungan seluruh indikator yang sudah ditentukan dalam penelitian efektivitas penerapan SIA berbasis komputer pendekatan DBMS pada KSP Asri Sari Utama Mandiri, sebagai berikut.

1 = indikator independensi data

2 = indikator standarisasi data

$3=$ indikator integrasi data

4 = indikator waktu

$5=$ indikator keamanan data

6 = indikator variasi laporan
Efektivitas penerapan penerapan SIA berbasis komputer pendekatan DBMS jika dinilai secara total, dengan perhitungan sebagai berikut.

1) $\mathrm{a}=5 \times 27 \times 15=2.025$

$b=1 \times 27 \times 15=405$

2) Range skor $=a-b$

$$
\begin{aligned}
& =2.025-405 \\
& =1.620
\end{aligned}
$$

3) Interval: $\mathrm{c}=\frac{a-b}{5}$

$$
\begin{aligned}
& =\frac{2.025-405}{5} \\
& =324
\end{aligned}
$$

Berdasarkan perhitungan yang telah dipaparkan maka rentang nilai untuk masing-masing kriteria penilaian dapat ditentukan dengan formulasi berikut.

a. Kriteria Sangat Efektif (KSE) = $1.701<$ KSE $\leq 2.025$

b. Kriteria Efektif $(\mathrm{KE})=1.377<\mathrm{KE} \leq$ 1.701

c. Kriteria Cukup Efektif $(\mathrm{KCE})=1.053$ $<\mathrm{KCE} \leq 1.377$

d. Kriteria Kurang Efektif $(\mathrm{KKE})=729$ $<\mathrm{KKE} \leq 1.053$

e. Kriteria Tidak Efektif (KTE) $=405 \leq$ KTE $\leq 729$

\section{HASIL DAN PEMBAHASAN HASIL}

Penerapan Sistem Informasi Akuntansi Berbasis Komputer dengan Pendekatan Database Management System pada Koperasi Simpan Pinjam Asri Sari Utama Mandiri terdiri dari tiga proses: (1) input data dilakukan dengan cara memasukkan data transaksi yang terjadi pada tanggal kejadian ke dalam database. Pada KSP Asri Sari Utama Mandiri input data dilakukan dengan teliti sehingga mengurangi terjadinya kesalahan pemasukkan data. Input data pada KSP Asri Sari Utama Mandiri memperhatikan ketepatan waktu, integrasi dan keseragaman dalam penggunaan nama akun maupun penetapan bunga simpan pinjam. (2) pemrosesan data pada DBMS terkait dengan keseragaman dan integrasi. Hal ini menjadi penting ketika seluruh 
sistem pemrosesan data berkembang sesuai dengan rencana yang telah secara otomatis pada DBMS. (3) output atau hasil keluaran dari pengolahan data transaksi KSP Asri Sari Utama Mandiri berupa laporan keuangan. Laporan keuangan yang dihasilkan seperti laporan Arus Kas, Neraca dan Selisih Hasil Usaha (SHU). Laporan keuangan ini diolah secara otomatis oleh sistem yang digunakan oleh KSP Asri Sari Utama Mandiri serta dapat dicetak sewaktu-waktu oleh pengguna informasi untuk pengambilan keputusan.

Efektivitas Penerapan Sistem Informasi Akuntansi Berbasis Komputer dengan Pendekatan Database disusun. Pemrosesn data ini dilakukan

Management System pada Koperasi Simpan Pinjam Asri Sari Utama Mandiri, termasuk dalam kriteria efektif. Hal ini dapat dilihat dari perolehan masingmasing indikator, yaitu berdasarkan indikator independensi data dengan perolehan total skor 1.689 termasuk kriteria efektif dapat dilihat dalam Tabel 1. Indikator standarisasi data dengan kriteria efektif dapat dilihat dalam Tabel 2 , indikator integrasi data dengan kriteria efektif dapat dilihat dalam Tabel 3 , indikator waktu dengan kriteria efektif dapat dilihat dalam Tabel 4, indikator keamanan data dengan kriteria efektif dapat dilihat dalam Tabel 5, dan indikator variasi laporan dengan kriteria sangat efektif dapat dilihat dalam Tabel 6.

Tabel 1. Indikator Independensi Data

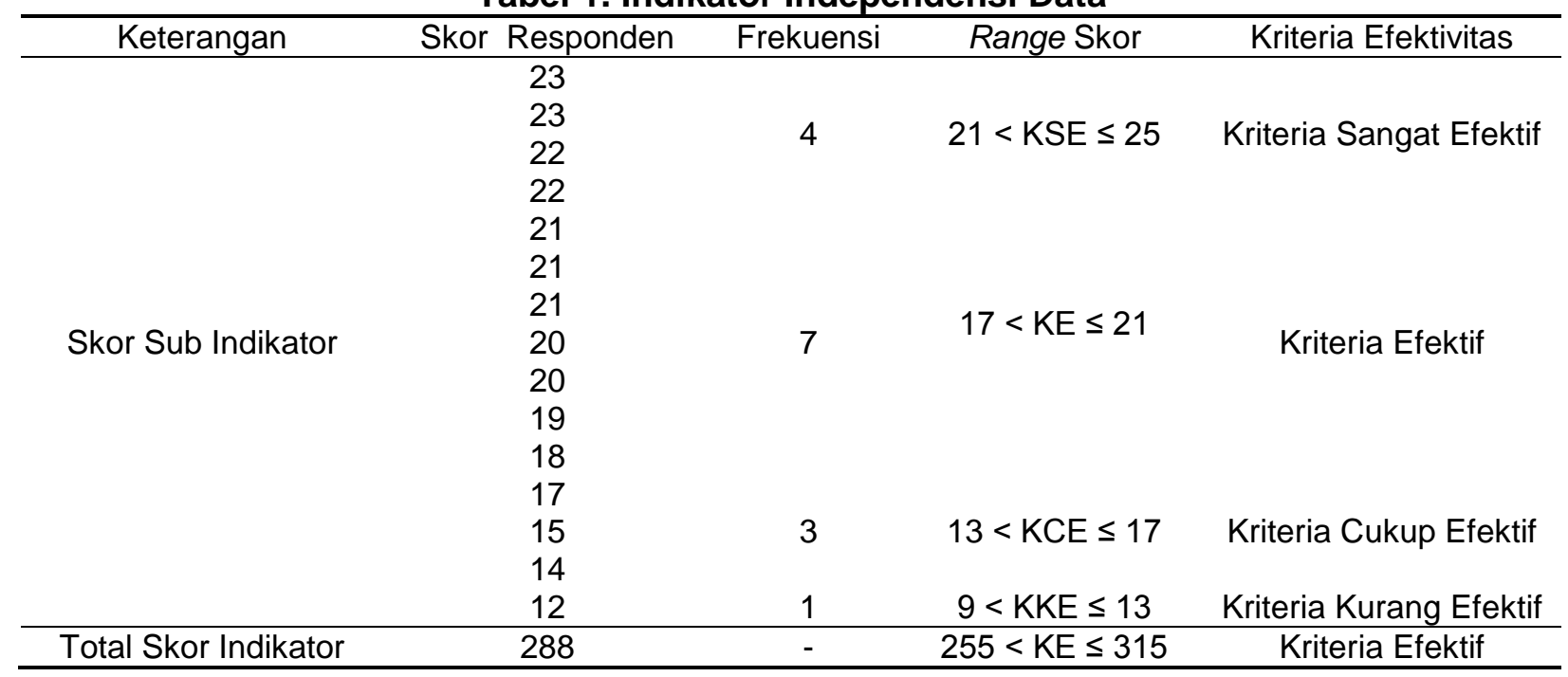

Tabel 2. Indikator Standarisasi Data

\begin{tabular}{|c|c|c|c|c|}
\hline Keterangan & Skor Responden & Frekuensi & Range Skor & Kriteria Efektivitas \\
\hline & 19 & & & \\
\hline & 19 & & & \\
\hline & 19 & & & \\
\hline & 19 & & & Kriteria Sangat \\
\hline & 19 & 9 & $16,8<\mathrm{KSE} \leq 20$ & Ffektif \\
\hline & 18 & & & \\
\hline & 18 & & & \\
\hline \multirow[t]{8}{*}{ Skor Sub Indikator } & 18 & & & \\
\hline & 17 & & & \\
\hline & 16 & & & \\
\hline & 15 & 3 & $13,6<\mathrm{KE} \leq 16,8$ & Kriteria Efektif \\
\hline & 14 & & & \\
\hline & 13 & & & \\
\hline & 13 & 3 & $10,4<\mathrm{KCE} \leq 13,6$ & Kriteria Cukup Efektif \\
\hline & 12 & & & \\
\hline Total Skor Indikator & 249 & - & $216<\mathrm{KE} \leq 264$ & Kriteria Efektif \\
\hline
\end{tabular}


Kesimpulan dari Tabel 1 dan Tabel 2 bahwa dari ke bahwa penerapan SIA berbasis komputer dengan pendekatan DBMS pada KSP Asri Sari Utama Mandiri dari indikator independensi data dengan perolehan total skor 288 jika dibandingkan dengan kriteria efektivitas maka termasuk kriteria efektif dan indikator standarisasi data dengan hasil analisis efektivitas termasuk kriteria efektif dengan perolehan skor 249.

Tabel 3. Indikator Integrasi Data

\begin{tabular}{|c|c|c|c|c|}
\hline Keterangan & Skor Responden & Frekuensi & Range Skor & Kriteria Efektivitas \\
\hline \multirow{15}{*}{ Skor Sub Indikator } & 25 & \multirow{7}{*}{7} & \multirow{7}{*}{$21<\mathrm{KSE} \leq 25$} & \multirow{7}{*}{$\begin{array}{c}\text { Kriteria Sangat } \\
\text { Efektif }\end{array}$} \\
\hline & 23 & & & \\
\hline & 23 & & & \\
\hline & 23 & & & \\
\hline & 23 & & & \\
\hline & 23 & & & \\
\hline & 22 & & & \\
\hline & 21 & & & \multirow{6}{*}{ Kriteria Efektif } \\
\hline & 21 & & & \\
\hline & 21 & 6 & $17<\mathrm{KE} \leq 21$ & \\
\hline & 20 & 0 & $16-n c-21$ & \\
\hline & 19 & & & \\
\hline & 19 & & & \\
\hline & 17 & \multirow{2}{*}{2} & \multirow{2}{*}{$13<\mathrm{KCE} \leq 17$} & Kriteria Cukup \\
\hline & 14 & & & Efektif \\
\hline Total Skor Indikator & 314 & - & $255<\mathrm{KE} \leq 315$ & Kriteria Efektif \\
\hline
\end{tabular}

Tabel 4. Indikator Waktu

\begin{tabular}{|c|c|c|c|c|}
\hline Keterangan & Skor Responden & Frekuensi & Range Skor & Kriteria Efektivitas \\
\hline \multirow{3}{*}{ Skor Sub Indikator } & $\begin{array}{l}25 \\
25 \\
23 \\
22 \\
22 \\
22\end{array}$ & 6 & $21<\mathrm{KSE} \leq 25$ & $\begin{array}{c}\text { Kriteria Sangat } \\
\text { Efektif }\end{array}$ \\
\hline & $\begin{array}{l}21 \\
21 \\
21 \\
21 \\
20 \\
20 \\
17\end{array}$ & 6 & $17<\mathrm{KE} \leq 21$ & Kriteria Efektif \\
\hline & $\begin{array}{l}16 \\
16\end{array}$ & 3 & $13<\mathrm{KCE} \leq 17$ & $\begin{array}{c}\text { Kriteria Cukup } \\
\text { Efektif }\end{array}$ \\
\hline Total Skor Indikator & 312 & - & $255<\mathrm{KE} \leq 315$ & Kriteria Efektif \\
\hline $\begin{array}{l}\text { Kesimpulan d } \\
\text { Tabel } 4 \text { bahwa } \\
\text { penerapan SIA b } \\
\text { dengan pendekatan } \\
\text { Asri Sari Utama Ma } \\
\text { integrasi data deng }\end{array}$ & $\begin{array}{l}\text { Tabel } 3 \text { dan } \\
\text { ari ke bahwa } \\
\text { oasis komputer } \\
\text { BMS pada KSP } \\
\text { diri dari indikator } \\
\text { perolehan total }\end{array}$ & & \multicolumn{2}{|c|}{ 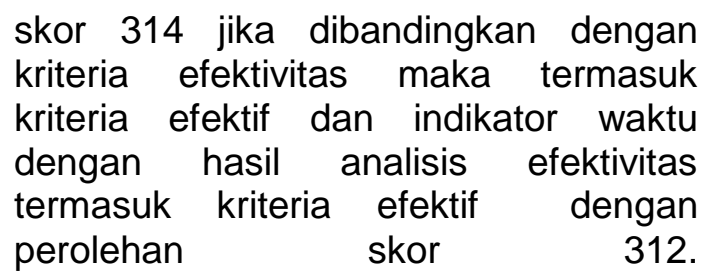 } \\
\hline
\end{tabular}


Tabel 5. Indikator Keamanan data

\begin{tabular}{ccccc}
\hline Keterangan & Skor Responden & Frekuensi & Range Skor & Kriteria Efektivitas \\
\hline 20 & & & \\
& 19 & & & \\
& 19 & & & Kriteria Sangat \\
Efektif & & & \\
& 19 & & & Kriteria Efektif \\
& 19 & & $13,6<$ KE $\leq 16,8$ & \\
Skor Sub Indikator & 19 & & & Kriteria Cukup \\
& 16 & & & Efektif \\
\hline Total Skor Indikator & 16 & & $10,4<$ KCE $\leq 13,6$ & Kriteria Efektif \\
\hline
\end{tabular}

Tabel 6. Indikator Variasi Laporan

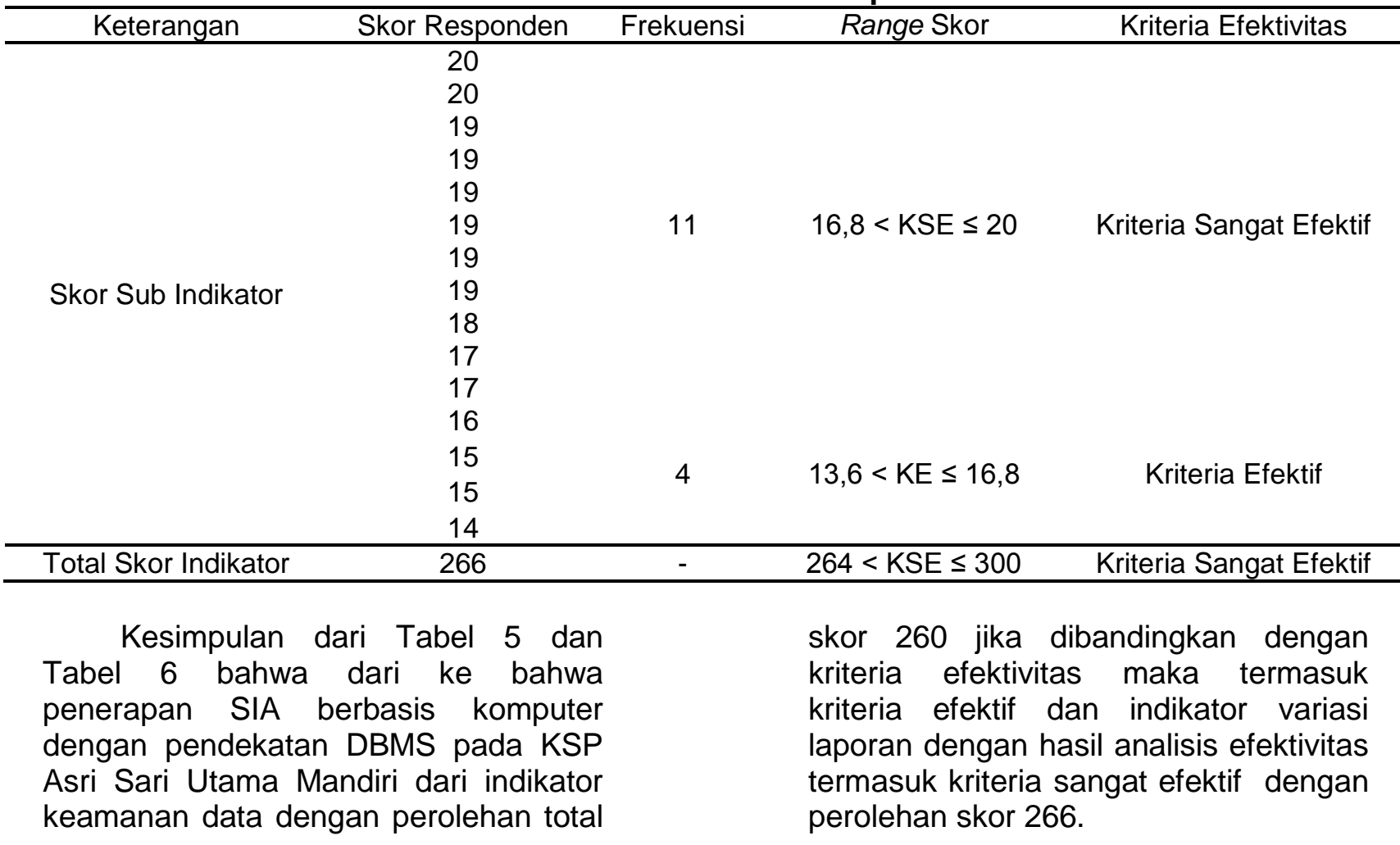

Tabel 7. Efektivitas SIA berbasis komputer dengan pendekatan DBMS

\begin{tabular}{lccc}
\hline \multicolumn{1}{c}{ Keterangan } & Skor Indikator & Range Skor & Kriteria Efektivitas \\
\hline Independensi data & 288 & $255<$ KE $\leq 315$ & Kriteria Efektif \\
Standarisasi data & 249 & $216<$ KE $\leq 264$ & Kriteria Efektif \\
Integrasi data & 314 & $255<$ KE $\leq 315$ & Kriteria Efektif \\
Waktu & 312 & $216<$ KE $\leq 264$ & Kriteria Efektif \\
Keamanan data & 260 & $216<$ KE $\leq 264$ & Kriteria Efektif \\
Variasi laporan & 266 & $264<$ KSE $\leq 300$ & Kriteria Sangat Efektif \\
\hline Total Skor & 1.689 & $1.377<$ KE $\leq 1.701$ & Kriteria Efektif \\
\hline
\end{tabular}




\section{Pembahasan}

Berdasarkan hasil penelitian, penerapan SIA berbasis komputer dengan pendekatan DBMS memiliki peranan penting dalam kegiatan KSP Asri Sari Utama Mandiri. Peranan tersebut seperti kemudahan dalam input data yang dapat dilakukan hanya pada salah satu komputer karena sistem sudah terintegrasi dengan efektif, selain itu pengolahan data transaksi yang terjadi setiap harinya dapat diolah secara otomatis sehingga menghasilkan laporan keuangan (output) yang dibutuhkan oleh para pemakai informasi. Hal ini dapat dilihat dari hasil analisis data yang diperoleh melalui enam indikator yaitu indenpendensi data, standarisasi data, integrasi data, waktu, keamanan data, dan variasi laporan. Temuan ini sesuai dengan pendapat Husein (2004) yang menyatakan bahwa untuk mengelola informasi secara efektif menjadi sumber daya yang bernilai, pengembangan sistem informasi akuntansi modern akan lebih baik jika menggunakan teknologi informasi dan jaringan komputer.

KSP Asri Sari Utama Mandiri menerapkan SIA berbasis komputer dengan pendekatan DBMS memiliki kriteria independensi data yang efektif. Hal tersebut dapat dilihat dari hasil analisis efektivitas pada indikator independensi data. Temuan ini membuktikan bahwa SIA berbasis komputer dengan pendekatan DBMS ini pada indikator independensi data mampu kemudahan dalam menjalankan sistem. Sesuai dengan pemaparan Wilkinson (2002), yang menyebutkan dengan adanya independensi data memungkinkan perubahan dilakukan secara lebih mudah dan cepat.

Hasil analisis efektivitas pada indikator standarisasi data termasuk Kriteria Efektif. Hal ini menunjukkan bahwa standarisasi data pada sistem ini seperti dalam menggunakan nama akun-akun. Selain itu, standarisasi data dapat juga dapat dilihat dari ketentuanketentuan koperasi seperti penetapan bunga tabungan dan pinjaman dalam suatu periode tertentu. Hal ini memudahkan KSP Asri Sari Utama Mandiri dalam mengolah data transaksinya. Temuin ini juga sesuai dengan pemaparan Wilkinson (2002) mengenai standarisasi bisa juga disebut dengan konsistensi data. Misalnya elemen data yang mencerminkan jumlah penjualan hanya memiliki satu nama, satu arti dan satu format. Jadi harus kompatibel dengan setiap program yang mengakses database.

Indikator integrasi data, hasil analisis efektivitas dinyatakan termasuk Kriteria Efektif. Integrasi data pada SIA berbasis komputer dengan pendekatan DBMS pada KSP Asri Sari Utama Mandiri terdapat satu tempat penyimpanan (repository) data terpusat sehingga dapat digunakan oleh beberapa karyawan. Data yang di-input di komputer satu akan dapat dibaca dalam komputer lainnya. Hal inilah yang memberi kemudahan dalam mengolah transaksi pada KSP Asri Sari Utama Mandiri. Temuan ini juga sejalan dengan Wilkinson (2002) yang menyatakan pendekatan DBMS menyediakan penyimpanan data terpusat untuk digunakan oleh berbagai user dan program aplikasi.

Berdasarkan hasil penelitian, efektivitas pada indikator waktu termasuk Kriteria Efektif. Hasil analisis tersebut menunjukkan bahwa kecepatan SIA berbasis komputer dengan pendekatan DBMS dalam input, pengolahan dan penyajian transaksi sudah melebihi program manual seperti Microsoft Excel. Selain itu, hasil analisis efektivitas pada indikator yang kelima yaitu keamanan data termasuk dalam Kriteria Efektif. Keamanan data yang disimpan terjamin karena adanya sistem password untuk setiap karyawan yang berkepentingan, selain itu adanya menu peringatan atau early warning apabila salah memencet tombol pada keyboard. Temuan ini didukung oleh Hall (2002) yang menyatakan DBMS menyediakan sebuah lingkungan yang terkontrol untuk membantu pemakai mengakses database. Selama pemrosesan, DBMS secara periodik 
membuat file-file backup untuk database fisik. Jika terjadi kerusakan (kegagalan penyimpanan, kesalahan program atau tindakan kejahatan) yang menyebabkan database tidak bisa digunakan, DBMS dapat pulih ke versi sebelumnya yang dianggap benar. Hasil efektivitas dari indikator variasi laporan termasuk Kriteria Sangat Efektif. Variasi laporan yang dihasilkan oleh SIA berbasis komputer dengan pendekatan DBMS pada KSP Asri Sari Utama Mandiri seperti laporan arus kas, neraca dan selisih hasil usaha (SHU). Selain itu, sistem juga mampu menghasilkan laporan bulanan secara otomatis dan dapat diminta sewaktu-waktu. Asumsi peneliti mengenai temuan penelitian ini adalah melalui penerapan SIA berbasis komputer dengan pendekatan DBMS dapat melancarkan aktivitas KSP Asri Sari Utama Mandiri dalam hal input, proses dan menyajikan laporan keuangan.

Berdasarkan hasil penelitian dari keenam indikator, efektivitas penerapan SIA berbasis komputer dengan pendekatan DBMS termasuk Kriteria Efektif. Temuan ini sesuai dengan hasil temuan Aditya Primatika (2009) Fakultas Ekonomi, Universitas Brawijaya meneliti tentang Analisis Efektivitas Sistem Informasi Akuntansi Penggajian Karyawan, diperoleh hasil bahwa sistem informasi akuntansi penggajian yang telah dijalankan sudah efektif. Hal itu dapat dilihat dari fungsifungsi, struktur organisasi, dan dokumentasi sudah sesuai dengan teori yang telah didapat pada masa perkuliahan.

Berdasarkan hasil penelitian, maka dapat diketahui bahwa penerapan SIA berbasis komputer dengan pendekatan DBMS pada KSP Asri Sari Utama Mandiri memberikan kemudahan dalam mengolah data akuntansi secara otomatis serta adanya integrasi dalam jaringan seperti local area network yang mempermudah dalam input, proses dan penyajian laporan keuangan.

\section{SIMPULAN DAN SARAN Simpulan}

\begin{abstract}
Penerapan Sistem Informasi Akuntansi (SIA) Berbasis Komputer dengan Pendekatan Database Management System (DBMS) pada Koperasi Simpan Pinjam Asri Sari Utama Mandiri terdapat tiga proses yaitu input transaksi, proses pada DBMS dan output yang berupa penyajian laporan keuangan. Efektivitas penerapan SIA berbasis komputer dengan pendekatan DBMS pada KSP Asri Sari Utama Mandiri berada pada kriteria efektif. Hal ini dapat dilihat dari perolehan masing-masing indikator, yaitu berdasarkan indikator independensi data dengan efektif (288), indikator standarisasi data dengan kriteria efektif (249), indikator integrasi data dengan kriteria efektif (314), indikator waktu dengan kriteria efektif (312), indikator keamanan data dengan kriteria efektif (260), dan indikator variasi laporan dengan kriteria sangat efektif (266)..
\end{abstract}

\section{Saran}

Berdasarkan simpulan hasil penelitian dapat diajukan saran, yaitu penerapan SIA berbasis komputer dengan pendekatan DBMS pada KSP Asri Sari Utama Mandiri sebaiknya tetap dipertahankan dan lebih ditingkatkan mengenai pengetahuan di bidang SIA berbasis komputer sehingga membantu karyawan koperasi dalam penerapan SIA berbasis komputer dengan pendekatan DBMS yaitu dapat dilakukan dengan cara kerjasama antara karyawan dengan tehknisi DBMS agar selalu dijaga, sehingga gangguan pengolahan data dalam SIA berbasis komputer dengan pendekatan DBMS dapat teratasi dengan baik dan benar. Selain itu karyawan diharapkan lebih teliti dalam meng-input data nasabah .

\section{DAFTAR PUSTAKA}

Bodnar, George H dan William S. Hopwood. 2003. "Sistem Informasi Akuntansi".Edisi ke-8. Yogyakarta: Andi. 
------. 2006. "Sistem Informasi Akuntansi".Edisi ke-9

Hall, James A. 2002. Sistem Informasi Akuntansi. Jakarta: Salemba Empat.

Husein, Muhammad Fakhri. 2004. "Sistem Informasi Akuntansi" Yogyakarta: Akademi Manajemen Perusahaan YKPN.

Primatika, Aditya. 2009. "Analisis Efektivitas Sistem Informasi Akuntansi Penggajian Karyawan". Malang: Skripsi Fakultas Ekonomi Universitas Brawijaya.

Siregar, Syofian. 2010. "Statistika Deskriptif untuk Penelitian."
Jakarta: PT Rajagrafindo Persada.

Sugiyono. 2012. "Metode Penelitian Kuantitatif Kualitatif dan $R \& D$ ". Bandung: Alfabeta.

------. 2013. "Metode Penelitian Pendidikan Pendekatan Kuantitatif Kualitatif dan $R$ \& $D$ ". Bandung: Alfabeta.

Sukardi. 2003. "Metodologi Penelitian Pendidikan". Jakarta: PT Bumi Aksara.

Wilkinson, Joseh W.. 2002. "Sistem Akuntansi dan Informasi", Edisi ketiga. Jakarta: Erlangga. 